\title{
Diagnostic investigation of patients with chronic polyneuropathy: evaluation of a clinical guideline
}

\author{
N R Rosenberg, P Portegies, M de Visser, M Vermeulen
}

\begin{abstract}
Objective-(1) To evaluate a clinical guideline for the diagnostic investigation of patients presenting with signs and symptoms (present for longer than 6 weeks) suggesting a chronic polyneuropathy. (2) To investigate the contribution of electrophysiological studies to a focused search for aetiology in these patients. Methods-A chart review was carried out of a consecutive group of outpatients in 1993-7 at a university department of neurology, with signs and symptoms suggesting a polyneuropathy in whom the diagnostic investigation had been carried out according to a recently introduced guideline. Diagnostic tests were performed and final diagnoses were made.

Results-Unnecessary investigations were carried out in $108(51 \%)$ of 213 patients and too few tests in $23(11 \%)$ of these patients. In $82(48 \%)$ of the 172 patients who fulfilled the inclusion criteria neurophysiological tests did not contribute to the final diagnosis. Neurophysiological criteria for demyelination were fulfilled in only $13(8 \%)$ of the 172 patients.

Conclusion-In patients presenting with signs and symptoms of chronic polyneuropathy the number of tests in the diagnostic investigation can be considerably reduced. In patients with signs and symptoms of polyneuropathy, providing the clinical phenotype is typical, in the presence of diabetes mellitus, renal failure, HIV infection, alcoholism, or use of potentially neurotoxic drugs further investigations are non-contributory. The significance of electrophysiological studies in the investigation of patients with polyneuropathy is rather to separate sensorimotor neuropathies from pure sensory neuropathies than to distinguish between demyelinating and axonal neuropathies.

(F Neurol Neurosurg Psychiatry 2001;71:205-209)
\end{abstract}

Keywords: chronic polyneuropathy; diagnostic investigation; electrophysiological studies

Polyneuropathy is a syndrome with many different causes. ${ }^{1}$ As polyneuropathy occurs often in many patients many diagnostic tests have to be carried out to find a cause. At our department of neurology there seemed to be great variation among clinicians and no consensus about the number and selection of tests in patients with polyneuropathy. Therefore, in 1993 it was decided to develop a guideline for the diagnostic investigation.

The guideline was mainly based on expert opinion. It consisted of a two step procedure. Firstly, the most often occurring causes of polyneuropathy had to be demonstrated or excluded. Thereafter, if a cause had not been found, investigations were aimed at rare causes. Electrophysiological studies were considered to play a key part, initially in confirming the diagnosis of polyneuropathy and subsequently by directing the search for the cause. ${ }^{1-5}$

Five years after introduction of this guideline it was decided to investigate whether it was efficient and effective. The results clearly indicate that the diagnostic investigation, including electrophysiology, should be much more focused. Based on these results a new guideline is proposed.

\section{Patients and methods}

THE GUIDELINE 1993

The guideline was focused on chronic polyneuropathy (signs and symptoms present for longer than 6 weeks) and is shown in figure 1 . When a chronic polyneuropathy was suspected by clinicians at our outpatient department, a routine set of laboratory tests and electrophysiological studies were performed (part 1). The laboratory tests included erythrocyte sedimentation rate, haemoglobin, mean cell volume, white cell count, platelets, sodium, potassium, creatinine, alkaline phosphatase, glucose, blood urea nitrogen, and $\gamma$-glutamyltransferase (GGT).

When polyneuropathy was confirmed by electrophysiological studies and when diabetes mellitus, uraemia, or alcoholism had been excluded, patients entered part 2 of the protocol. The electrophysiological findings determined whether the patient belonged to one of the following categories: (1) uniform demyelinating neuropathies, (2) non-uniform demyelinating neuropathies, (3) pure motor axonal neuropathies, (4) sensorimotor axonal neuropathies, or (5) pure sensory axonal neuropathies. Within each category there were additional laboratory tests to reach a final diagnosis.

\section{PATIENTS}

Included in the study were outpatients who had presented between 1993 and 1997 with symptoms or signs of a polyneuropathy after introduction of the diagnostic guideline. Exclusion criteria were second opinion, investigation already (partly) carried out, polyneuropathy already diagnosed, and missing follow up data. 
Age, sex, medical history, medication, and alcohol consumption were recorded. Neurological history, neurological examination, and test results were extracted from the files.

EVALUATION PROCEDURE

A group of three senior neurologists (PP, MdV, and $\mathrm{MV}$ ) was formed for the evaluation of this guideline. Two of them (MdV, MV) have a special expertise in neuromuscular diseases, and one (PP) in neurological disorders associated with systemic diseases.

Each member of the team was offered relevant information from the files and the results of the routine set of laboratory tests. On the basis of these data consensus had to be reached on a presumptive diagnosis and whether electrophysiological studies were indicated. If the last was affirmed the team had access to the results of the electrophysiological investigation. This enabled them to assign the patient to the diagnostic route of one of the five categories and to make a diagnosis. The diagnosis in the medical record was then disclosed to the team, who subsequently had to decide whether too many, too few, or a sufficient number of diagnostic tests were performed to reach a diagnosis. At the end of the procedure for each patient a final diagnosis was established based on all available data, including follow up of at least 1 year.

\section{ELECTROPHYSIOLOGY}

Using standard techniques electrodiagnostic studies were performed according the guideline. Skin temperature was maintained between $32^{\circ} \mathrm{C}$ and $35^{\circ} \mathrm{C}$. The electrophysiological studies included motor and sensory conduction velocities in at least two arm nerves and one leg nerve, $\mathrm{F}$ responses of the ulnar nerve and peroneal nerve, $\mathrm{H}$ reflex of the soleus muscle, and EMG of distal arm and leg muscles.

Polyneuropathy was classified as demyelinating when fulfilling the neurophysiological criteria for demyelination as defined by the ad hoc subcommittee.$^{67}$ If these criteria were not fulfilled, but there was neurophysiological evidence of polyneuropathy, the polyneuropathy was classified as axonal. There was no separate classification for a demyelinating neuropathy with an axonal component or the reverse, the so called mixed forms. Patients with neurophysiological test results not consistent with polyneuropathy were classified as no polyneuropathy.

Guideline 1993-7

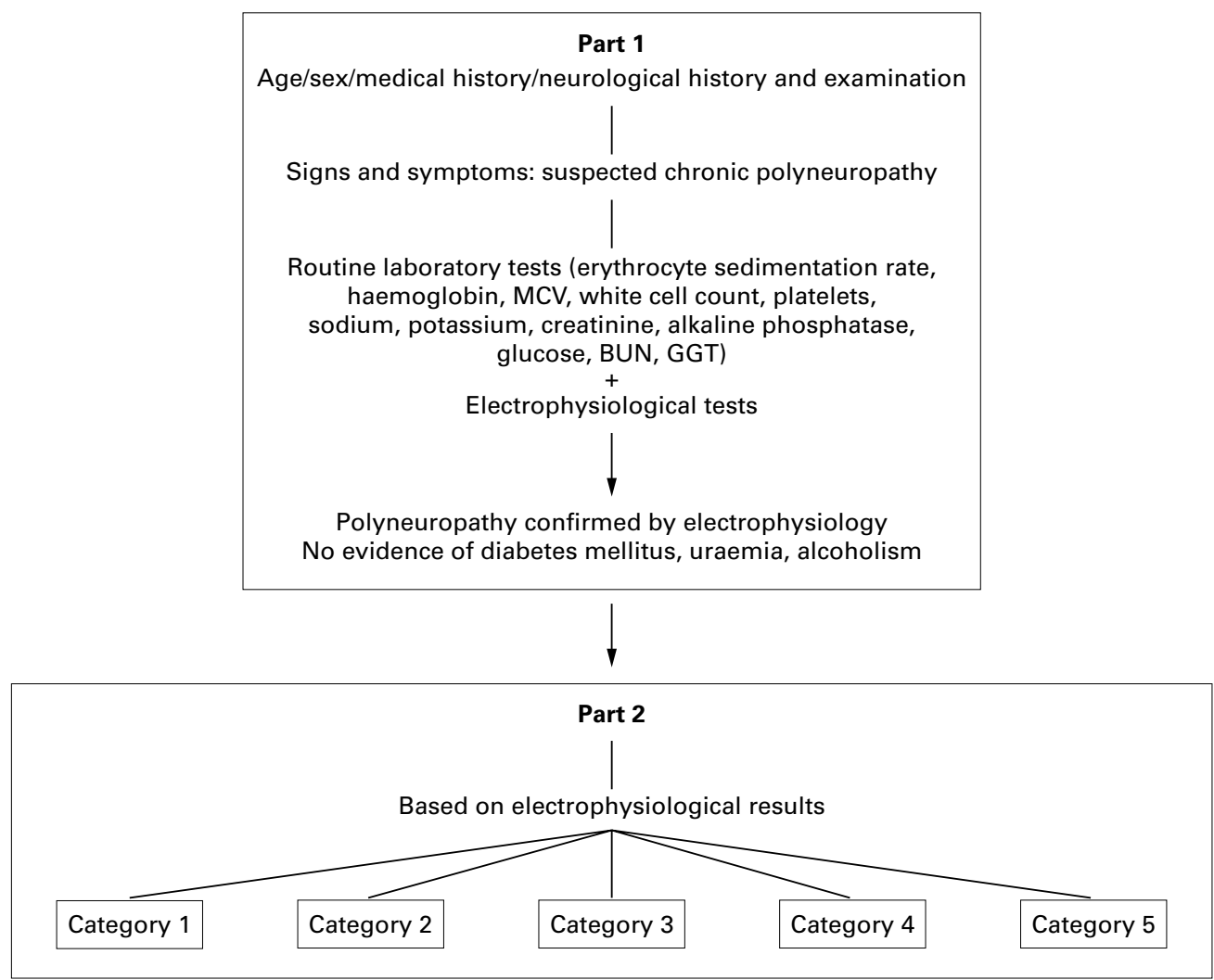

Category 1: uniform demyelinating neuropathy

Category 2: non-uniform demyelinating neuropathy

Category 3: pure motor axonal neuropathy

Category 4: pure sensory axonal neuropathy

Category 5: sensorimotor axonal neuropathy

Figure 1 Guideline 1993-7. 
Table 1 Results of evaluation of 157 patients suspected of chronic polyneuropathy, according to part 1 of the guideline

\begin{tabular}{|c|c|c|c|c|}
\hline & $\begin{array}{l}\text { Polyneuropathy with known } \\
\text { cause }(n=105)\end{array}$ & $\begin{array}{l}\text { Polyneuropathy cause } \\
\text { disclosed by part } 1(n=11)\end{array}$ & No neuropathy $(n=32)$ & $\begin{array}{l}\text { Signs and symptoms of } \\
\text { neuropathy, not } \\
\text { confirmed by } \\
\text { electrophysiology }(n=9)\end{array}$ \\
\hline $\begin{array}{l}\text { Patients with unnecessary investigations } \\
\text { Patients with too few investigations } \\
\text { Number of electrophysiological studies } \\
\text { Number of patients with no electrophysiological studies } \\
\text { Unnecessary electrophysiological studies } \\
\text { Results of electrophysiologic tests }\end{array}$ & $\begin{array}{l}\text { Diabetes mellitus }(\mathrm{n}=60) \\
\text { HIV }(\mathrm{n}=21) \\
\text { Alcoholism }(\mathrm{n}=11) \\
\text { Drug induced }(\mathrm{n}=7) \\
\text { Renal failure }(\mathrm{n}=6) \\
\mathrm{n}=69 \\
\mathrm{n}=0 \\
\mathrm{n}=73 \\
\mathrm{n}=32 \\
\mathrm{n}=69 \\
\text { Demyelinating }(\mathrm{n}=6) \\
\text { Axonal, sensorimotor }(\mathrm{n}=53) \\
\text { Axonal, pure sensory }(\mathrm{n}=9) \\
\text { Axonal, pure motor }(\mathrm{n}=5)\end{array}$ & $\begin{array}{l}\mathrm{n}=4 \\
\mathrm{n}=0 \\
\mathrm{n}=11 \\
\mathrm{n}=0 \\
\mathrm{n}=3 \\
\text { Axonal, sensorimotor }(\mathrm{n}=9) \\
\text { Axonal, pure sensory }(\mathrm{n}=2)\end{array}$ & $\begin{array}{l}\mathrm{n}=10 \\
\mathrm{n}=0 \\
\mathrm{n}=29 \\
\mathrm{n}=3 \\
\mathrm{n}=10 \\
\text { No neuropathy }(\mathrm{n}=29)\end{array}$ & $\begin{array}{l}\mathrm{n}=0 \\
\mathrm{n}=6 \\
\mathrm{n}=3 \\
\mathrm{n}=6 \\
\mathrm{n}=0 \\
\text { No neuropathy }(\mathrm{n}=3)\end{array}$ \\
\hline
\end{tabular}

^Some patients have more than one unnecessary investigation.

\section{Results}

Between 1993 and 1997, 473 patients were seen at our outpatient clinic in whom the diagnosis polyneuropathy was considered by staff members of this clinic. Excluded from this study were 260 patients. Reasons for exclusion were: second opinion (95), already investigated (37), known with polyneuropathy (87), no follow up data (seven) and missing files (34).

Of the 213 included patients, 137 were men, 76 women; mean age was 62 (range 26-93) years.

Tables 1 and 2 show the results of investigations according to parts 1 and 2, respectively, of the guideline.

Half of the 60 patients known with diabetes and showing signs and symptoms of polyneuropathy had been referred by general practitioners and the other half by specialists, mostly specialists in internal medicine. In 10 out of 30 patients referred by general practitioners and in 12 out of 30 patients referred by specialists, the referring physician had not considered the diagnosis polyneuropathy. In the other patients the reason for referring was to investigate whether the symptoms were caused by diabetic neuropathy.

Neurophysiological studies were performed in 172 out of $213(81 \%)$ patients. In 82 patients the results of these studies did not contribute to the final diagnosis, because the cause of polyneuropathy was obvious (56 diabetes, three alcoholism, five uraemia, six HIV, two drug induced), or polyneuropathy was considered very unlikely after history and examination $(n=10)$. In all of these 82 patients, the diagnosis had not changed after the electrophysiological studies. In the group of 41 patients who were not electrophysiologically investigated, evaluation disclosed that in six patients electrophysiological studies would have been informative, as the diagnosis of polyneuropathy was questionable.

Thirteen out of $172(8 \%)$ patients fulfilled the criteria of a demyelinating polyneuropathy. In 10 out of 13 patients the demyelinating neuropathy was recognised on clinical signs and symptoms, medical history, and laboratory tests. This was the case in our patients with polyneuropathy due to diabetes, uraemia, alcoholism, Guillain-Barré syndrome, leprosy, medication, and paraproteinaemia due to multiple myeloma. In three patients electrophysiological studies disclosed a demyelinating neuropathy (CMT-I, x-CMT, and distal acquired demyelinating symmetric neuropathy (DADS). ${ }^{8}$

In 108 of 213 (51\%) patients' ancillary investigations did not contribute to a final

Table 2 Evaluation of 56 patients with chronic polyneuropathy, according to part 2 of the guideline

\begin{tabular}{|c|c|c|c|c|c|}
\hline \multirow[b]{2}{*}{$\begin{array}{l}\text { Results of electrophysiological } \\
\text { tests }\end{array}$} & \multirow[b]{2}{*}{$\begin{array}{l}\text { Uniform demyelinating } \\
(n=2)\end{array}$} & \multirow[b]{2}{*}{$\begin{array}{l}\text { Non-uniform demyelinating } \\
(n=5)\end{array}$} & \multicolumn{3}{|l|}{ Axonal } \\
\hline & & & Pure sensory $(n=6)$ & $\begin{array}{l}\text { Purely motor } \\
(n=0)\end{array}$ & Sensorimotor $(n=43)$ \\
\hline Clinical features & \multirow{2}{*}{$\begin{array}{l}\text { Consistent with } \\
\text { hereditary demyelinating } \\
\text { neuropathy }(n=2) \\
n=0\end{array}$} & \multirow{2}{*}{$\begin{array}{l}\text { Consistent with } \\
\text { non-uniform demyelinating } \\
\text { neuropathy }(n=4) \\
n=1\end{array}$} & Pure sensory $(n=6)$ & & $\begin{array}{l}\text { Pure motor }(n=2) \\
\text { Pure sensory }(n=19) \\
\text { Sensorimotor }(n=22)\end{array}$ \\
\hline $\begin{array}{l}\text { Patients wrongly assigned to } \\
\text { this group }\end{array}$ & & & $\mathrm{n}=3$ & & $\mathrm{n}=4$ \\
\hline $\begin{array}{l}\text { Patients with unnecessary } \\
\text { investigations }\end{array}$ & $\mathrm{n}=1$ & $\mathrm{n}=2$ & $\mathrm{n}=3$ & & $\mathrm{n}=19$ \\
\hline $\begin{array}{l}\text { Patients with too few } \\
\text { investigations }\end{array}$ & $\mathrm{n}=0$ & $\mathrm{n}=0$ & $\mathrm{n}=1$ & & $\mathrm{n}=16$ \\
\hline \multirow[t]{8}{*}{ Final diagnosis } & CMT-I $(n=1)$ & $\begin{array}{l}\text { Sequelae of Guillain-Barré } \\
\text { syndrome }(n=2)\end{array}$ & $\begin{array}{l}\text { Vitamin B12 deficiency } \\
(\mathrm{n}=1)\end{array}$ & & CIAP $(n=32)$ \\
\hline & \multirow[t]{7}{*}{$\mathrm{X}$ linked $\mathrm{CMT}(\mathrm{n}=1)$} & Multiple myeloma $(\mathrm{n}=1)$ & $\begin{array}{l}\text { Paraneoplastic } \\
\text { polyneuropathy }(n=1)\end{array}$ & & CMT-II $(n=3)$ \\
\hline & & Leprosy $(n=1)$ & Sarcoidosis $(n=1)$ & & Hypothyroidism $(n=2)$ \\
\hline & & \multirow[t]{5}{*}{$\mathrm{DADS}^{\star}$ neuropathy $(\mathrm{n}=1)$} & \multirow[t]{5}{*}{$\begin{array}{l}\text { Idiopathic pure sensory } \\
\text { neuropathy }(n=3)\end{array}$} & & $\begin{array}{l}\text { Sequelae of critical illness } \\
\text { polyneuropathy }(n=2)\end{array}$ \\
\hline & & & & & Vitamin $\mathrm{B} 12$ deficiency $(\mathrm{n}=1)$ \\
\hline & & & & & Paraneoplastic polyneuropathy $(n=1)$ \\
\hline & & & & & Sclerodermia $(\mathrm{n}=1)$ \\
\hline & & & & & Burning feet by diltiazem $(n=1)$ \\
\hline
\end{tabular}

${ }^{\star}$ DADS $=$ Distal acquired demyelinating symmetric. 
Table 3 Sensory neuropathies ${ }^{14}$

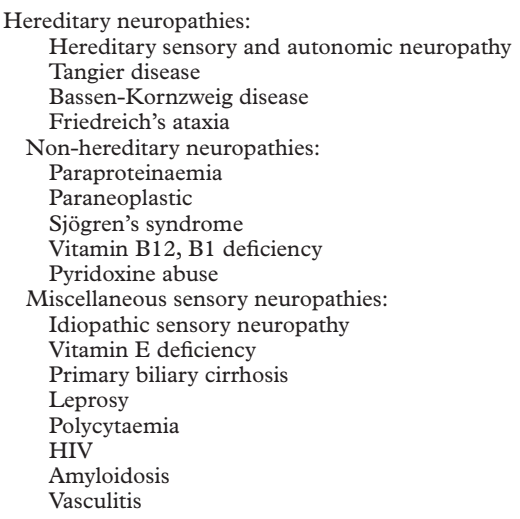

diagnosis. These tests included neurophysiological studies in 82 patients and routine laboratory investigations in 36 with a known cause (for example, glucose in patients with known diabetic mellitus). Thirty three were classified in two separate categories instead of one. Fifty six miscellaneous tests were carried out.

Too few investigations were done to establish a diagnosis in 23 out of $213(11 \%)$ of the patients.

\section{Discussion}

Our study shows that the importance of neurophysiological studies seems to be different from that suggested in the literature..$^{9-12}$ In patients with signs and symptoms of a distal symmetric polyneuropathy with a duration of more than 6 weeks and a known cause for this polyneuropathy, confirmation of peripheral neuropathy by neurophysiological studies is unnecessary. In our study this was the case in more than half $(55 \%)$ of all referred patients.

It has been stressed, and rightly so because of therapeutic options, that the distinction between demyelinating and axonal neuropathies is of importance in directing the search for the cause of the neuropathy. However, the incidence of a demyelinating polyneuropathy seems to be very low $(8 \%)$ in an unselected referred patient population. Moreover, demyelinating neuropathy could be recognised on clinical grounds in most patients who were shown to have this type of neuropathy.

Electrophysiological studies are crucial in patients with clinical signs of pure sensory or pure motor neuropathies, as in these patients electrophysiological tests may disclose subclinical involvement of either the sensory or motor nerve. Neurophysiological investigations in patients with polyneuropathy of unknown cause should therefore rather focus on distinguishing sensory from sensorimotor neuropathy than on the differentiation of demyelinating from axonal neuropathy. This distinction between pure sensory and sensorimotor neuropathy has important diagnostic consequences (table 3)..$^{13} 14$

The number of unnecessary tests in patients with sensorimotor axonal neuropathies can mainly be explained by the consideration of rare causes such as vasculitic peripheral neuropathy. Serological tests to demonstrate vasculitis were performed in 44 patients, but none of the patients finally had a diagnosis of vasculitic neuropathy. The number of tests was also high in this group because no distinction was made between pure sensory and sensorimotor neuropathy.

The proportion of patients with diabetic polyneuropathy in this study was unexpectedly large. In one third of the patients the referring physician had not recognised diabetic neuropathy as the cause of the neurological symptoms. When patients with diabetes mellitus and signs and symptoms indicating polyneuropathy were referred with the question whether these could be explained by diabetic neuropathy, blood tests and electrophysiological studies never disclosed another diagnosis.

Based on the results of this study, recommendations can be given for the investigation of patients with signs and symptoms of chronic polyneuropathy:

- In patients with signs and symptoms of chronic polyneuropathy, providing the clinical phenotype is typical, in association with a known cause of peripheral neuropathy, additional blood tests and electrophysiological studies are not informative

- If there is no known cause, ancillary studies should initially aim at the demonstration of diabetes, alcohol misuse, or renal failure. In patients who are on medication, neurotoxicity should be considered. ${ }^{15}$ Whether HIV neuropathy should be included in the differential diagnosis or not depends on the incidence of HIV in the population of referred patients, which in our centre is high

- If the above mentioned causes are considered unlikely, electrophysiological studies should be carried out to assign the patients to the categories shown in the guideline (fig 1).

In patients with a possible demyelinating polyneuropathy, diagnosis has to be confirmed by electrophysiological studies, as this diagnosis may have important therapeutic consequences. In the other patients it is more relevant to determine whether there is a pure sensory or a sensorimotor neuropathy. Pure motor neuropathies are extremely rare. In patients with pure sensory neuropathy specific causes such as Sjögren's syndrome, paraneoplastic neuropathy, and hereditary disorders should be considered. If these disorders have been excluded and systemic disease is unlikely, a diagnosis of chronic idiopathic sensory neuropathy remains. ${ }^{13}$

In the group of patients with a sensorimotor neuropathy, chronic idiopathic axonal neuropathy is by far the most frequent subtype. These patients are characterised by clinical signs and symptoms of a chronic polyneuropathy, and a slowly progressive course. Electrophysiology identifies the axonal nature. The diagnosis chronic idiopathic axonal polyneuropathy can only be made if routine blood tests are normal and diabetes, renal failure, alcohol misuse, drug induced neuropathy, hereditary neuropathy, systemic disease, paraproteinaemia, vitamin B12 and B1 deficiency, or hypothyroidism have been excluded or are 
unlikely. Recognition of this usually nondebilitating type of neuropathy, of which the cause is as yet unknown, is important as these patients tend to be subjected to many unnecessary and often repeated ancillary investigations. ${ }^{16} 17$

Sural nerve biopsy in our opinion is indicated in a limited number of patients, in whom we consider the diagnosis of a vasculitis neuropathy or an amyloid neuropathy.

In patients in whom the diagnosis Chromic inflammatory demyelmating polyneuropathy is considered a sural nerve biopsy seems of no additional value. ${ }^{18}$

In cases of $\operatorname{IgM} \kappa$ paraproteinaemic neuropathy the results of a sural nerve biopsy have no consequences for treatment.

In conclusion, we have shown that the number of tests in patients with signs and symptoms of polyneuropathy could be considerably reduced. In patients who have diabetes mellitus, renal failure, use neurotoxic drugs, or are known alcohol misusers, further investigations are non-contributory. In patients in whom the cause of neuropathy is not obvious electrophysiological studies are informative because they may show a demyelinating neuropathy, or subclinical involvement of either the sensory or motor nerve. The distinction between pure sensory and sensorimotor neuropathies is of importance for further differential diagnosis.

1 Notermans NC, Wokke JHJ, Jennekens FGI. Clinical work-up of the patient with a polyneuropathy. In: Jong JMBV de, Vinken PJ, Bruyn GW, et al, eds. Handbook of clinical neurology. Hereditary neuropathies and spinocerebellar atrophies. Amsterdam: Elsevier Science, 1991;61:30-70.
2 Donofrio PD, Albers JW. AAEM minomonograph 34: polyneuropathy, classification by nerve conduction studies and electromyography. Muscle Nerve 1990;13:889-903.

3 Dyck PJ, Oviatt RF, Lambert EH. Intensive evaluation of referred unclassified neuropathy yields improved diagnosis. Ann Neurol 1981;10:222-6.

4 McLeod JG, Tuck RR, Pollard JD, et al. Chronic polyneuropathy of undetermined cause. 7 Neurol Neurosurg Psychiatry 1984;47:530-5.

5 Daube JR. Nerve conduction studies. In: Aminoff M, ed. Electrodiagnosis in clinical neurology, 3rd ed. New York: Churchill Livingstone, 1992:283-326.

6 Report from an Ad Hoc Subcommittee of the American Academy of Neurology AIDS Task Force. Research criteria for diagnosis of chronic inflammatory demyelinating polyneuropathy (CIDP). Neurology 1991;41:617-18.

7 Bromberg MB. Comparison of electrodiagnostic criteria for primary demyelination in chronic polyneuropathy. Muscle Nerve 1991;14:968-76.

8 Barohn RJ, Lois CA, Smith DE. Chronic acquired demyelinating polyneuropathy variants. The Communicator 1999.

$9 \mathrm{McLeod} \mathrm{JG}$. Investigation of peripheral neuropathy. $7 \mathrm{Neu}$ rol Neurosurg Psychiatr 1995;58:274-83.

10 Dyck PJ, Dyck JB, Grant IA, et al. Ten steps in characterizing and diagnosing patients with a polyneuropathy. Neurology 1996;47:10-17

11 Logigian EL, Kelly JJ, Adelman S. Nerve conduction and biopsy correlation in over 100 consecutive patients with suspected polyneuropathy. Muscle Nerve 1994;17:101-20.

12 Kimura J. Nerve conduction studies and electromyography. In: Dyck PJ, Thomas PK, Low PA, et al, eds. Peripheral neuIn: Dyck PJ, Thomas PK, Low PA, et al, eds. Peripheral neu-
ropathy. 3rd ed. Philadelphia: WB Saunders, 1993:598644.

13 Wokke JH, van Dijk GW. Sensory neuropathies including painful and toxic neuropathies. F Neurol 1997;244:209-21.

14 Van Dijk GW, Notermans NC, Kater L, et al. Sjögren's syndrome in chronic idiopathic axonal polyneuropathy. $f \mathrm{Neu}-$ rol Neurosurg Psychiatry 1997;63:376-8.

15 Jain KK. In: Jain KK, ed. Drug-induced neurological disorders. Kirkland, WA: Hogrefe and Huber, 1996:208-34.

16 Notermans NC, Wokke JHJ, Franssen H, et al. Chronic idiopathic polyneuropathy presenting in middle or old age: a clinical and electrophysiological study of 75 patients. 7 Neurol Neurosurg Psychiatry 1993;56:1066-71.

17 Notermans NC, Wokke JH, van der Graaf Y, et al. Chronic idiopathic axonal polyneuropathy: a 5 year follow up. 7 Neurol Neurosurg Psychiatry 1994;57:1525-7.

18 Molenaar DSM, Vermeulen M, de Haan R. Diagnostic value of sural nerve biopsy in chronic inflammatory demyelinating polyneuropathy. $f$ Neurol Neurosurg Psychiatry 1998;64:84-9. 